\title{
VIGENCIA DEL MITO DEL BUEN SALVAJE
}

\author{
IVAN ALEXANDER MUÑOZ CRIOLLO \\ Doctor en filosofía de la Universidad de Zurich \\ Licenciado en filosofía de la Universidad del Valle \\ Docente del CEILAT
}

\begin{abstract}
RESUMEN
Mito del buen salvaje se ha llamado a la tendencia a idealizar éticamente a las sociedades que tradicionalmente han sido catalogadas como primitivas. Propiamente nace este mito con las expediciones de Colón, pero tuvo su apogeo durante la época de la ilustración como instrumento de autocrítica de los países civilizados. Este artículo se propone mostrar el origen de este mito, su influjo en la teoría política y en la educación, así como su pervivencia en el discurso intelectual cotidiano.
\end{abstract}

Palabras Clave: Buen salvaje, estado de naturaleza, ilustración, natura lapsa, romanticismo.

\begin{abstract}
As a myth of the noble savage has been called the tendency to ethically idealize the societies that traditionally have been classified as primitive. Properly this myth was born with the expeditions of Columbus, but it had its peak during the time of the Enlightenment as an instrument of self-criticism of civilized countries. This article aims to show the origin of this myth, its influence on political theory and education, as well as its permanence in everyday intellectual discourse.
\end{abstract}

Key Words: Enlightenment, natura lapsa, noble savage, romanticism, state of nature.

\section{Oeconomia naturae y natura lapsa}

Varios mitos justifican la idea de que todo lo que sale de las manos de la naturaleza, sale bien, es armónico. No solo se ve esto en el Antiguo Testamento, cuando Dios llamó en cada momento buena a su creación ("Y Dios vió que era bueno”), también se ve en la idea de un ser humano con características similares a las de Dios en el mito judeocristiano.

Al tiempo, existen mitos que tratan de justificar la idea de un mundo que se disuelve y decae, por ejemplo entre los antiguos griegos el mito de la edad de oro que aparece en Trabajos y días de Hesíodo. A la edad de oro de la humanidad le siguió la de plata, a esta la 
de bronce, luego la edad de los héroes y la degeneración finaliza con la edad de hierro. En este mito se muestra como la primera generación de hombres -que tras su desaparición terminó como démon protector de los mortales- bajo Cronos vivía sin preocupaciones, sin vejez, en un campo lleno de frutos. Tras otras generaciones de hombres cada vez más imperfectas, la generación actual, la de hierro, disuelve relaciones entre padres, hermanos, amigos y huéspedes y se complace en la injusticia y la violencia. Nuestro tiempo sería así un mal sin remedio, una época en que los dioses abandonan a la humanidad, los últimos en abandonarla son Aidos (la vergüenza) y Némesis (castigo divino). Ovidio, al comienzo de Las metamorfosis, replica el mito. Según él la sociedad actual estaría en la edad de hierro, donde se taló para navegar, se empezó a medir la tierra, y no conformes con arar la tierra, se toma de sus entrañas minerales para armas y para comercio, además de disolverse completamente los vínculos de amor entre hombres. Implícitamente, en este relato se muestra una crítica a la técnica.

El mismo Hesíodo muestra en otro mito cómo Pandora desata los males que ahora aquejan a la humanidad, y que sin esta no existirían:

Antes vivían sobre la tierra las tribus de hombres libres de males y exentas de la dura fatiga y las penosas enfermedades que acarrean la muerte a los hombres, pues al punto en la miseria los hombres empiezan a envejecer.
Pero aquella mujer [Pandora], al quitar con sus manos la enorme tapa de una jarra los dejó diseminarse y procuró a los hombres lamentables inquietudes (Hesíodo, 2006, p. 67).

La contraposición que se ve aquí entre lo que se podría llamar mitos optimistas y mitos pesimistas acerca de la naturaleza, la ha llamado el historiador Dieter Groh (2003) la contraposición entre oeconomia naturae y natura lapsa. Ambas comprensiones de la naturaleza terminan formando concepciones del humano totalmente contrapuestas. Groh las llama modelos culturales, campos simbólicos ("marco de orientación construido culturalmente"), base o presupuesto de teorías de diferentes campos del saber (Groh, 2003, p. 15). Estos modelos no tienen que darse necesariamente puros, por ejemplo, algunos cristianos pensaron en un ser humano imperfecto por culpa del pecado, no obstante también en una perfección de la creación material o visible.

El mito del buen salvaje pretende mostrarnos que un hombre apegado a la naturaleza, el primer producto de esta naturaleza, el "hombre primitivo", es bueno física y moralmente, aunque está condenado a caer debido a la superioridad militar de la civilización que quiere eliminarlo a asimilarlo a sus inmorales costumbres. Esto es un ejemplo de natura lapsa, un ejemplo de caída de la naturaleza perfecta por culpa de lo antinatural, la civilización, una especie de nueva caída en 
pecado original, nueva pérdida de la inocencia.

\section{La caída del estado de naturaleza}

Un ejemplo de natura lapsa es la historia del pecado original, una historia cuyo protagonista fue san Agustín y cuyos antagonistas fueron primero el monje Pelagio y luego el teólogo Juliano. Básicamente, según san Agustín, tras el pecado original la naturaleza humana quedó gravemente afectada. Que Adán y Eva hubiesen sentido vergüenza por estar desnudos y hubiesen cubierto sus partes pudendas -san Agustín interpreta el Génesis como una crónica fiel, no como una alegoría- muestra que estas partes algo malo tienen: Así como se desobedeció a Dios, nuestras partes pudendas también nos desobedecen (Flasch, 2008, p. 19) y además, después de esto, el acto sexual ya no se puede llevar a cabo sin "malos pensamientos". San Agustín interpreta mal un fragmento clave de la Biblia (Rom. 5, 12), pues no usa la versión en griego, solo la vulgata, y concluye que de algún modo la humanidad estaba "virtualmente" en Adán en el momento de su primer pecado, estaba in lumbis de Adán, en su lomo: "In lumbis eius erat genus humanum".

El pecado se convierte en san Agustín en hereditario, en una especie de enfermedad de transmisión sexual (todo humano fue concebido en pecaminosidad) o cuando menos en un defecto genético (Leonhardt, 2004, p. 180). De esa pecaminosidad con que nace el hombre solo lo puede librar la gracia divina. La virtud hecha por los propios medios no es más que un orgullo, no muestra del amor a Dios. De allí la famosa frase atribuida a san Agustín: "Las virtudes de los paganos no son más que sus vicios más brillantes".

Dios hizo al hombre a su imagen y semejanza, según la tradición judeocristiana. Acerca del significado de imagen y semejanza se ha discutido mucho. Mientras los católicos concluyeron con Hugo de san Víctor en el siglo XII que la imagen se refiere al amor a la verdad y que la semejanza se refiere al amor a la virtud y a Dios (y esta fue la parte afectada por el pecado), los primeros protestantes con Lutero y Calvino concluyeron que "imagen y semejanza" son una sola cosa, sinónimos usados en una figura literaria conocida como endíadis ("uno mediante dos"), como cuando se dice que alguien está con uno "en las duras y las maduras" o que alguien está en un lugar "de carne y hueso". Mientras que para los católicos es la voluntad y el amor a Dios lo comprometido por el pecado, para los protestantes incluso la razón ha sido permeada por el pecado, y el hombre sin la gracia divina sería incapaz de lograr superarlo (Leonhardt, 2004, p. 179).

El caso del pecado original es otro caso de natura lapsa: se supone una naturaleza humana buena originalmente que termina decayendo, excepto en versiones como las de Meister Eckhart, donde se piensa en la ima- 
gen y semejanza como semillas que el hombre debe dejar crecer a lo largo de su vida, no como un pasado perdido. Tanto católicos como protestantes piensan, basados en san Pablo y en san Agustín, que la naturaleza humana, debido al pecado heredado, está tan radicalmente degenerada que es imposible por los propios méritos ser bueno, que solo por una especie de milagro, la gracia divina, es posible que el hombre sea redimido; este premio, sin embargo, no tiene lógica humana en el sentido del trabajo y el pago (como en la parábola de los trabajadores en el viñedo). Dios brinda su gracia a quien quiere y nadie puede mediante buenas obras asegurarse sin la voluntad divina la entrada al cielo. Esta doctrina tiene muchos matices en los católicos, pues ellos consideran que la libertad no está perdida, solo corrompida, y que las buenas obras pueden ayudar a ganar la gracia (Leonhardt, 2004, p. 221).

Según lo dicho, nadie puede estar libre de pecado. Incluso rechazando la teoría del contagio del pecado mediante el tipo de concepción propia de los humanos, quedaría la idea del pecado que se propaga con el ejemplo, por normalización de conductas pecaminosas.

\section{Colón en el paraíso}

Cuando Colón encontró poblada América no se hizo muchas preguntas, después de todo pensaba que había llegado a alguna isla cercana de Cipango; no obstante, tomó posesión de la isla como propiedad de los reyes de España. Lo primero que sorprendió a Colón, lo primero que nombra en su informe, es la desnudez de los aborígenes, pues, como se señaló, se suponía que después del pecado cometido por Adán y Eva todos los seres debían sentir vergüenza por la desnudez propia y la búsqueda de vestido para sus partes "nobles", el vestir ciertas partes, se pensaba algo universal. ¿No tenían los aborígenes el pecado original? Por otro lado, Colón consignó que el cuerpo y la cara de ellos era bello, que eran mansos y generosos, vivían sin armas, sin ley y sin idolatría (Reding, 2009, p. 47). Pero no solo los humanos, la naturaleza también le pareció prodigiosa: los colores, los frutos, las flores, los árboles, los peces, los pájaros y su canto (Reding, 2009, p. 49). La serpiente en ese paraíso eran los cariba (llamados por Colón caniba - pensaba que los aborígenes pronunciaban mal, que se referían a los habitantes de las tierras del Gran Khan), tribus antropófagas que cazan a las demás, los caníbales. El buen salvaje y el caníbal coexistían, pues, como en la novela Robinson Crusoe, y aunque el caníbal despierta cierto horror, despierta inicialmente curiosidad y admiración (Reding, 2009, p. 90). Calibán, personaje de $L a$ tormenta de Shakespeare, puede considerarse el retrato literario del caníbal, del salvaje, del negro, del otro que no alcanza la cultura dominante (Reding, 2015).

Montaigne hace una aguda defensa del Caníbal en sus ensayos al argumentar que 1) llamamos bárbaro a 
lo que no corresponde a nuestras costumbres; 2) pensamos que nuestras costumbres, religión y política son superiores a las de los demás; 3) salvajes no son quienes son frutos espontáneos de la naturaleza, sino quienes se han desviado del camino y corrompido su gusto, los que prefieren lo artificial, es decir, los bárbaros se hallan más próximos a la candidez y pureza de lo natural, mientras que en Europa se vive en una sociedad llena de vicios; 4) es menos salvaje comerse al enemigo de guerra ya muerto, que torturar a los vivos con fuego, con mordiscos de animales, con el pretexto religioso; 5) aunque pierdan los salvajes contra la civilización, pierden triunfalmente y 6) hipócritamente los descalificamos por no parecerse a nosotros: "buena cosa parece todo esto, pero, ¿vamos a tener en consideración a unos individuos que no llevan calzones?" (Montaigne, 1984, p. 161).

No fue por la existencia de canibalismo o por la amenaza de canibalismo que se acabaron las "buenas" relaciones entre indígenas y exploradores. La relación idílica con algunos de los indígenas tuvo que acabar una vez los huéspedes abusaron de los anfitriones, pero debe quedar constancia de que la visión primera de Colón, la paradisíaca, la compartieron marineros de otras latitudes - además de Vespucci (Reding, 2009, p. 75): varios europeos abandonaron su tripulación para quedarse en tierra con los aborígenes, como lo informa Bitterli (1981, p. 97), estos tránsfugas de la civilización en África occidental, Canadá, Malasia o
Tahití fueron perseguidos por sus propios superiores: la civilización no permite desertores.

El caso de la admiración de Colón por los salvajes no fue el primero. Ciertamente, lo que se mostrará a continuación no son más que contrajemplos de lo que parece haber sido la tendencia etnocentrista en la cultura europea. Podrían servir, sin embargo, para atacar tópicos muy extendidos. Se sabe que Homero admiraba a los probos etíopes, y para los bárbaros troyanos nunca hay palabras de descalificación, Heródoto reconoció gracias a sus viajes la relatividad de los juicios interculturales, el dominio del nomos sobre physis, esto es de la convención sobre aquello presuntamente natural (en esto coincidía con los sofistas), además de reconocer culturas más antiguas y más espléndidas que la griega (Landmann, 1961, p. 24). Tucídices notó que los griegos de antaño se parecían mucho a los bárbaros por estar siempre armados y dedicados a la piratería e Hipócrates mostraba que las diferencias entre culturas están mediadas por diferencias entre climas y geografía (Landmann, 1961, p. 25). La lista podría ampliarse mucho más, pero hay un caso que no puede faltar, el texto de Tácito Germania: las virtudes de los salvajes germanos descritas por Tácito (valentía, piedad, honradez, grandes valores morales, poco lujo en el vestir), sirven para mostrar a los romanos su propia decadencia moral. Aquí ya se usa el mito del buen salvaje para la crítica. Cabe anotar que Tácito, a diferencia de Colón, parece 
que tuvo conocimiento de los germanos de segunda mano.

Luego de Colón, luego de saber que se había arribado a un nuevo continente y en modo alguno a Asia, surgió la pregunta por el origen de los habitantes de América:

Arias Montaño sostuvo en el siglo XVI que los descendientes de Heber, el padre de los hebreos, y de Sem, uno de los hijos de Noé, poblaron respectivamente el Perú y Brasil. Otros pensaron en los cananeos, echados de las tierras bíblicas por las invasiones hebraicas; otros en fin, señalaban a los primos fenicios y cartagineses [...]. Los pueblos desaparecidos de origen mítico [...] reaparecían así en América. la historia universal no podía tener lagunas [...]. El origen semítico de los indios otorgaba derechos de primacía a los conquistadores (Vidart, 1987, p. $34)$.

Todavía los mormones sostienen que los habitantes de América descienden de los "lamanitas", descendientes a su vez de Abraham, y que tanto el color de su piel como el olvido de sus orígenes, lengua y creencias, se explica por un castigo impartido por Dios. Como quiera que sea, tanto la creencia de una nueva humanidad lejana del pecado original, como la idea de estar en un paraíso, terminó viéndose como un error, pues contra esto último se empezó a argumentar, especialmente con Buffon -quien nunca había pisado América-, que en América tanto la flora como la fauna se hacía pequeña y débil, degeneraba (además de pensar que América era un continente nuevo, hace poco emergido de las aguas). A este prejuicio se le enfrentaron férreamente Thomas Jefferson y Alexander von Humboldt, quienes se esforzaron por mostrar que tal juicio sólo podía ser motivado por el desconocimiento, y además, según Humboldt "las teorías de Buffon sobre la degeneración solo se habían popularizado porque 'halagaban la vanidad de los europeos'” (Wulff, 2017, p. 207).

En buena parte, la mirada humana que se tuvo hacia los habitantes originarios de América estuvo posteriormente mediada por las luchas de Fray Bartolomé de Las Casas y sus testimonios acerca del abuso de los españoles, además del trabajo de los jesuitas en Paraguay. Se les reconoció como humanos, se les salvó de la esclavitud y del maltrato, se les otorgó derechos especiales, en ocasiones aun en contra de los intereses colonialistas. Si bien se reconoció en parte a los indígenas como buenos salvajes, la labor de colonización y conquista, la historia guerrerista previa de España, los intereses económicos, les impidió actuar en consecuencia.

\section{Los ilustrados, los románticos y los salvajes}

Aunque el mito del buen salvaje recién durante la época de la ilustración se convierte en un mito, esto es, una creencia extendida sin mayor evidencia empírica, una especie de arquetipo al pensar sobre los pueblos originarios, se ha visto que las condiciones 
para su éxito estaban dadas en la cultura desde anteriores experiencias de contacto con otros pueblos, y desde la idea la oeconomia naturae. La buena naturaleza podría conservarse si se mantuviese aislada, pero en tiempos de exploradores no hay nada protegido, la buena naturaleza está condenada a caer, natura lapsa. El mito del buen salvaje es un mito romántico con el cual se ataca a la ilustración o se pretende prevenir sus abusos. ¿Cómo entender ilustración? ¿Cómo entender romanticismo?

La ilustración es un movimiento europeo que se caracteriza por la confianza puesta en la razón como instrumento de progreso común y en la razón como instrumento de comunicación universal; se caracteriza también por el cosmopolitismo, la redignificación de los sentidos como medio de conocimiento (de allí que en esta época surja la estética) y la atribución de un sentido en la historia (en esta época surge también la filosofía de la historia como disciplina). La ilustración intenta ver tras la diversidad cultural lo racional, permanente y común, tras el rito arbitrario la creencia compartida, además considera la ciencia como el gran logro de la humanidad, al igual que juzga el pasado, bien como un error del que se salió, bien como peldaños para el lugar ahora ocupado. Por el contrario, el romanticismo se caracteriza por resaltar lo regional, los fenómenos no asibles para la razón, el lado oculto, las tradiciones abstrusas que no son meras manifestaciones de los mismo; se caracteriza también por el interés por el origen como lo que señala la evolución del resto, la nostalgia por los tiempos pasados, además de recalcar la imposibilidad ocasional de comunicación entre culturas y épocas. La ciencia es mirada con desconfianza por ser desmitificadora, por ofrecer una verdad que deja de lado lo importante, pretendiendo captar la esencia. Mientras la labor del ilustrado se dirigía a la ciencia y a la pedagogía, la del romántico se orienta más a las artes y a la historia; mientras que los ilustrados se orientaban más a crear proyectos educativos de todo el saber de la época, los grandes teóricos del romanticismo escribían fragmentos y se oponían a la idea de sistema.

Tanto el modo cómo fue entendida la ilustración en cada reino, como la época de su apogeo, varía. Por eso, ceñirse a fechas resulta complicado. Ciertamente, se entiende por romanticismo el movimiento intelectual y artístico que siguió a la ilustración, pero sabemos que los cortes en los períodos históricos no son nunca fijos ni perpendiculares. No porque alguien viva en una determinada época piensa de un determinado modo. Por ejemplo, en pleno apogeo de la ilustración alemana, se encuentra figuras que están entre la ilustración y el romanticismo, como Herder, o que incluso son decididamente románticas y antilustradas (como Hamann). Estas figuras son difíciles de encasillar en una sola corriente de ideas. De aquí que sea posible decir que si bien el mito del buen salvaje nace en la época de la ilustración, lo cierto es que nace del romanticismo 
para criticar el orgullo ilustrado, en otras palabras, para criticar la exitosa $\mathrm{y}$ expansionista edad de hierro.

Más allá de la parte histórica del mito, en la cual se tendría que mostrar cómo desde las experiencias no solo de Colón y Vespucci, sino también de Álvares Cabral, Cartier y finalmente de Boungaville y Cook -entre muchos otros- se fue afianzando el mito, interesa aquí mostrar la parte filosófica, es decir, qué se puede hacer con esta idealización del aborigen, con este tópico. Primero se hablará de su uso en la crítica política, luego de su uso en la educación.

Los filósofos contractualistas clásicos suelen hacer un experimento mental en su intento de responder a la pregunta de por qué habría que obedecer al Estado, de ello sacan también las debidas consecuencias, esto es, a qué se debe tener derecho en el Estado. Básicamente proponen 1) pensar un estado de naturaleza, esto es, un momento en el cual no existen ni el Estado ni sus instituciones - da igual si este estado nunca ha existido, se trata de un experimento mental, 2) hay unas necesidades comunes insatisfechas en él, la única forma de satisfacerlas es hacer un pacto y 3) de este pacto surge el Estado. Habría, pues, un estado de naturaleza, un pacto $\mathrm{y}$ el Estado, tres estaciones. De cómo se imagine el estado de naturaleza va a depender luego la concepción de Estado y de sociedad que se tenga. Thomas Hobbes, por ejemplo, imaginaba el estado de naturaleza como especialmen- te cruel: al buscar cada cual su propio interés se terminaba lesionando los intereses de los demás, nadie podía ser siempre el más fuerte, otros podían atacarlo, las cosas eran de quien las tuviera solo durante el tiempo que lograra conservarlas, así pues, no había posibilidad de dedicarse a la ciencia o al trabajo sin ser luego perjudicado: "Y lo peor de todo, hay un constante miedo y un constante peligro de perecer de muerte violenta. Y la vida del hombre es solitaria, pobre, desagradable, brutal y corta" (Hobbes, 1994, p. 108). A este estado lo llama Hobbes "estado de guerra" en analogía al "mal tiempo", es decir, no la lluvia misma, sino la probabilidad de que llueva. Tal situación solo puede cambiarla un soberano que, al no ser parte del pacto, sino producto de él, no está ligado con obligaciones con ningún súbdito, es un soberano absoluto, el mal menor. Al predominio de la natura lapsa en la concepción de naturaleza humana, le sigue un estado totalitario como única forma de controlar esa naturaleza torcida.

Esta situación es, sin embargo, diferente en Locke y en Rousseau. Locke no plantea para nada un estado de naturaleza malo. Si el Estado se hace necesario es solo como árbitro, mediador entre conflictos que pudiesen surgir, pues los seres humanos no pueden ser juez y parte al tiempo. El Estado, además de ser árbitro, debe garantizar los derechos naturales de los ciudadanos. A la concepción optimista de la naturaleza humana, oeconomia natu- 
rae, le sigue una concepción liberal de Estado.

Rousseau, por su parte, en el discurso con el cual se hizo popular por ganar un premio de la academia de las ciencias de Dijón, Discurso sobre las ciencias y las artes, dejó claro que las ciencias y las artes han contribuido al ablandamiento de las personas y a la apariencia de virtud, fomentado la hipocresía y la miseria social, el saber inútil y el sufrimiento individual. Rousseau casi vuelve a una época en la que la curiosidad estaba mal vista, alabando la ignorancia feliz y el coraje que compensan otros con hipocresía, antepone el saber moral sobre la teoría moral (ser ignorante no significa ser corrompido), llamando "afeminamiento" a las buenas maneras, y a las ciencias simulacros de saber por estar alejadas de la virtud. Antes de la civilización, el mundo era mejor:

Antes de que esas horrorosas palabras tuyo y mío fuesen inventadas; antes de que existiese esa especie de hombres crueles y brutales que se llaman jefes y esa otra especie de hombres bribones y mentirosos que se llaman esclavos; antes de que hubiese hombres lo suficientemente abominables para atreverse a tener lo superfluo mientras otros hombres mueren de hambre [...] Se me asegura que hace largo tiempo que pasó de moda la quimera de la edad de oro. ¿Por qué no se añade aún que hace largo tiempo que ha pasado de moda la quimera de la virtud? (Rousseau, 1995, p. 75).
Rousseau plantea dos situaciones: en una los habitantes hacen un buen pacto, un contrato social donde domina la racional voluntad general, otra en que la gente es engañada y termina cediendo su libertad, adornando con guirnaldas sus cadenas, sometiéndose a la desigualdad. En lo que coinciden los dos casos es en una buena naturaleza humana. Esta "buena" tiene sus matices. Al igual que en el estadio al cual Kierkegaard llamó romántico no hay ni bueno ni malo hasta tomar la decisión de pasar al estadio ético -de allí que Fink-Eitel hable del origen "salvaje" de la filosofía existencial de Kierkegaard y Heidegger (Fink-Eitel, 1994)- afirma Rousseau que Hobbes no ha visto que la misma causa que impide a los salvajes usar de su razón, como lo pretenden los jurisconsultos, le impide al mismo tiempo abusar de sus facultades, como él mismo pretende; de tal modo que podría decirse que los salvajes no son malos precisamente porque no saben lo que es ser buenos, puesto que no es ni el desarrollo de las luces, ni el freno de la ley, sino la calma de las pasiones y la ignorancia del vicio quienes les impiden hacer el mal (Rousseau, 1995b, p. 148).

Con su concepción de naturaleza humana Rousseau puede criticar nuevamente la sociedad actual y notar que ella misma es la culpable de sus propias desgracias. Por ejemplo, ante el terremoto e incendio de Lisboa, ante las quejas vertidas en el poema de Voltaire en contra del optimismo de Leibniz y Pope -tragedia que no lo tocó a él mismo en absoluto-, Rousseau no 
puede más que responder en una carta a Voltaire, que no es culpa de la naturaleza que la gente arme 20.000 casas de 7 pisos una al lado de la otra, y que, de haber estado mejor distribuidas, no habrían pasado tantas desgracias: el mal está en la libertad del hombre, no en la naturaleza (Rousseau, 2008, p. 83).

De la misma concepción de oeconomia naturae se desprende que la buena educación consiste en dejar a la naturaleza hacer su trabajo con el niño: el niño debe aprender por sí mismo, no ser instruido por adulto alguno, mantenerse aislado. El trabajo educativo es, cuando menos al comienzo, negativo: prevenir la contaminación del niño con el mundo social, el mundo del adulto, el progreso de la natura lapsa. El niño debe ser un buen salvaje para ser un adulto de provecho.

\section{Los buenos salvajes hoy}

Según Steven Pinker, el mito del buen salvaje se lo puede hallar hoy en varias posturas ideológicas, por ejemplo en el actual respeto por todo lo natural (alimentos naturales, medicinas naturales, partos naturales) y en la desconfianza en lo elaborado, en el desprestigio del estilo autoritario, en el cuidado y la educación de los hijos y en la interpretación de los problemas sociales como defectos subsanables en nuestras instituciones, más que como tragedias inherentes a la condición humana (Pinker, 2014, p. 29).
Tal doctrina la llama Pinker mito porque niega la selección natural, pues un ser solo sobrevive si resulta vencedor en los conflictos, ganador en la competencia de la vida (2014, p. 95), y parece suponer que el ganador genético no es un campeón de la moral. Por otro lado, si bien reconoce que el estereotipo del "buen salvaje" sirvió para abusar de los aborígenes, también afirma que no es necesario idealizar a los aborígenes para poder reconocerles derechos, "como si el genocidio solo fuera execrable cuando las víctimas son simpáticas" (Pinker, 2014, p. 98). Finalmente, la doctrina del buen salvaje se instrumentaliza para justificar la bondad natural humana y considerar que "la violencia es un producto arbitrario del aprendizaje o un agente patógeno que nos invade desde el exterior" (Pinker, 2014, p. 489); con ello se pierde la oportunidad, argumenta Pinker, tanto de estudiar los mecanismos que disparan la violencia, como los que ayudan a controlarla.

Los problemas actuales con el mito del buen salvaje no se quedan allí. Se ha mostrado hasta ahora que el mito del buen salvaje en occidente hace parte de un modelo simbólico: si se tiene en cuenta la mera naturaleza del salvaje, lo intrínseco, sería oeconomia naturae, si se tiene en cuenta que no sobrevivirá al choque con la civilización occidental y terminarán inexorablemente corrompidos por las formas de esta, natura lapsa. Precisamente, este punto sirvió en la época de la ilustración a quienes tenían tendencias románticas, desconfiaban del progreso, para criticar los valores de su propia cultura, y si bien 
entre romanticismo y religión hubo fuertes vínculos, el dogma del pecado original fue dejado de lado en el caso de los salvajes la caída en pecado parecía ser la civilización, la inocencia irrecuperable era la pérdida de su identidad. ¿Qué pasa, sin embargo, cuando el mito del buen salvaje ya no es usado para criticar la propia civilización, sino para denigrar de las otras? Por supuesto, esto solo puede suceder cuando el mito del buen salvaje es usado por los propios "salvajes", los nuevos salvajes. Para decirlo más propiamente, cuando la alusión al buen salvaje se sobreentiende en las culturas afectadas por la "civilización", cuando se es parte de la cultura heredera -o desposeída- del buen salvaje. Allí es claro quienes son los buenos y su contraparte.

Hablar, por tomar un caso, del pensamiento castrante de occidente no es más que una fallida recuperación del otro, seña de ínfulas morales y regreso al mito de la pureza y al nacionalismo - además de eliminar las diferencias del otro y homogeneizarlo para inventar al enemigo. Contaminado con el nuevo pecado original, todo el pensamiento de occidente sería corrupto y el pensamiento válido nacería ahora en la tierra prometida americana. En suma, resentimiento que impide el diálogo. Ciertamente, como dice el proverbio sudafricano, el hacha olvida, el árbol no: no se puede desconocer los sufrimientos y el sometimiento de América, tampoco que no es cosa del pasado, pero mantener el esquema "noble salvaje / corrupta civilización" en nuestro caso (hecha la salvedad de las culturas originarias sobrevivientes en América) no nos lleva más lejos. La hermenéutica de la sospecha debe empezar con la sospecha sobre sí mismo. 


\section{REFERENCIAS}

Bitterli, U. (1981). Los "salvajes" y los "civilizados". El encuentro de Europa y ultramar. México D.F.: FCE.

Fink-Eitel, H. (1994). Die Philosophie und die Wilden. Über die Bedeutung des Fremden für die europäische Geistesgeschichte. Hamburg: Junius.

Flasch, K. (2008). Kampfplätze der Philosophie. Grosse Kontroversen von Augustin bis Voltaire. Frankfurt a.M.: Klostermann.

Groh, D. (2003). Schöpfung in Widerspruch. Deutungen der Natur und des Menschen von der Genesis bis zur Reformation. Frankfurt a.M.: Suhrkamp.

Hesíodo (2006). Trabajos y días en Teogonía - Trabajos y días - Escudo - Fragmentos - Certamen. Barcelona: Biblioteca Gredos / RBA coleccionables.

Hobbes, T. (1994). El leviatán I. Barcelona: Altaya.

Landmann, M. (1961). Antropología filosófica. México D.C.: UTEHA.

Leonhardt, R. (2004). Grundinformation Dogmatik. Gotinga: Vandenhoeck \& Ruprecht / UTB.

Montaigne, M. (1984). De los caníbales en Ensayos I. Barcelona: Orbis.

Pinker, S. (2014). Tabula rasa. La negación moderna de la naturaleza humana. Barcelona: Paidós.

Reding, S. (2009). El buen salvaje y el caníbal. México D.F.: Centro de Investigaciones sobre América Latina y el Caribe, UNAM.

Reding, S (2015). Vigencia de la imagen de Calibán en el pensamiento latinoamericano. Revista de Estudios Latinoamericanos (36-37), pp. 63-72.

Rousseau, J.J. (2008). Carta de Rousseau a Voltaire (18.08.1756) en Cartas morales y otra correspondencia filosófica. Madrid: Plaza y Valdés.

Rousseau, J.J. (1995b). Discurso sobre el origen de la desigualdad entre los hombres en Discurso sobre el origen de la desigualdad entre los hombres y otros escritos. Bogotá: Rei Andes.

Rousseau, J.J. (1995). Respuesta de Rousseau a Charles Bordes en Discurso sobre el origen de la desigualdad entre los hombres y otros escritos. Bogotá: Rei Andes.

Vidart, P. (1987). Ideología y realidad de América. Bogotá: Editorial Nueva América.

Wulff, A. (2017). La invención de la naturaleza. El nuevo mundo de Alexander von Humboldt. Bogotá: Taurus. 